\title{
A study of carpenter apprentices' spatial skills
}

\author{
Sebastien Cuendet ${ }^{1 *}$, Jessica Dehler-Zufferey ${ }^{1}$, Christoph Arn ${ }^{2}$, Engin Bumbacher ${ }^{3}$ and Pierre Dillenbourg ${ }^{1}$
}

\author{
${ }^{*}$ Correspondence: \\ sebastien.cuendet@epfl.ch \\ ${ }^{1}$ CHILI Lab, EPFL, Lausanne, \\ Swizterland \\ Full list of author information is \\ available at the end of the article
}

\begin{abstract}
Background: Spatial skills are crucial for carpentry and are a major learning objective in the initial vocational training of carpenter apprentices. Carpenters specifically need to develop the capability to switch between two-dimensional (2D) and three-dimensional (3D) representations. Previous studies have explored spatial skills, but never in the context of vocational education and training (VET). This study sheds light on the level and evolution of spatial skills in the initial vocational training of carpenter apprentices in Switzerland.
\end{abstract}

Methods: In this study, 726 subjects (98 females) who were either carpenter apprentices, apprentices of another profession, or high school students, took a test on spatial skills with three parts: mental rotation, paper folding, and orthographic projections. The first two parts are widely used tests for spatial skills, while the last one was specifically designed to address the 2D-3D transition that is a core skill of carpenters.

Results: Carpenter apprentices do have higher spatial skills than would be expected given their general school level. In particular, their spatial skills were found to be similar to those of high school students and superior to those of apprentices of another profession. Carpenters' spatial skills improve over the course of their apprenticeship. These findings confirm that spatial skills are trainable and suggest that the high spatial skills level of carpenter apprentices is due to a selection bias as well as to the training that they receive during their apprenticeship.

Conclusions: Carpenter apprentices improve their spatial skills over the time of their initial vocational training. As spatial skills are crucial in this profession, there is a need to develop further solutions that encourage further improvement of teaching and learning activities for spatial skills.

Keywords: Spatial skills; Carpentry; Apprenticeship

\section{Background}

The study reported in this paper was conducted as part of a Swiss research initiative that aims at supporting initial vocational education and training (VET) by means of technologies. The initiative explores and evaluates the benefits of tangible user interfaces (TUIs) to help carpenter apprentices learn their trade. TUIs are special kinds of computer interfaces that allow the user to control the computer through the manipulation of physical objects (Ishii and Ullmer 1997). The rationale behind using TUIs in the context of VET is that they are allow apprentices to continue to learn in a similar way as they currently do, that is with concrete learning material and hands-on activities (e.g. Manches and O’ Malley 2012; Do-Lenh et al. 2010).

(c) 2014 Cuendet et al.; licensee Springer. This is an Open Access article distributed under the terms of the Creative Commons Attribution License (http://creativecommons.org/licenses/by/2.0), which permits unrestricted use, distribution, and reproduction in any medium, provided the original work is properly credited. 
The aim of the first study within the project was to get familiar with the competences apprentices need and to inform the design of a tangible learning environment for carpenters. The results of a contextual inquiry in the apprentices schools and workplaces indicated that spatial skills should be the main focus of the project. The literature on spatial skills and vocational training in general is scarce, even though some studies have shown that the practitioners' approach to solving practical spatial tasks differs from that of students (Jurdak and Shahin 2001). This gap needs to be filled, as spatial skills are key in many vocationally trained professions (brick layers, metalworker, furniture maker, draftsman, etc.). This study is a first step in contributing data on spatial skills in VET. It does so by comparing carpenter apprentices' spatial skills to other similar populations, and by following their spatial skills development in a longitudinal approach.

The results of this study are of interest for three audiences: (1) it provides carpentry teachers and VET-focused instructional designers information about the current skill level and skill development of carpenter apprentices; (2) it provides new and original data on an often neglected segment of the population (apprentices) to researchers interested in spatial skills; and (3) it helps identify the specific needs for acquiring spatial skills, which in turn informs the design of the tangible learning environment.

The remainder of this introduction will illustrate how carpenters in general are trained, elucidate the contextual inquiry among carpentry professionals, and present an overview of existing literature on spatial skills research, before outlining the hypotheses addressed in this study.

\section{Carpenters in Switzerland}

In the Swiss vocational system, there are two different training paths: one for construction carpentry ("charpentier" in French, "Zimmermann" in German), and one for furniture making ("menuisier", "Schreiner"). This article focuses on construction carpenters, who construct large items, such as roof structures or even entire buildings (see Figure 1).

In 2010, with 1060 apprentices starting an apprenticeship, carpentry was the $19^{\text {th }}$ most popular profession by the number of apprentices starting an apprenticeship (Gaillard 2012). In 2011, 890 federal degrees for carpenters were delivered (869 men and 21 women) and there were 2887 people ( 29 women) enrolled in a carpenter apprenticeship, representing about $10 \%$ of all apprentices in the building trades.

The job of a carpenter is to prepare, cut, and assemble wood pieces to create the frames and roofs of buildings. Carpenters work on new buildings as well as on older ones that they renovate. Their job mainly consists of the following five steps:

1. Read and make sense of the plans produced by the architect (or the engineer).

2. Generate a working drawing based on the plans, at a 1:1 scale.

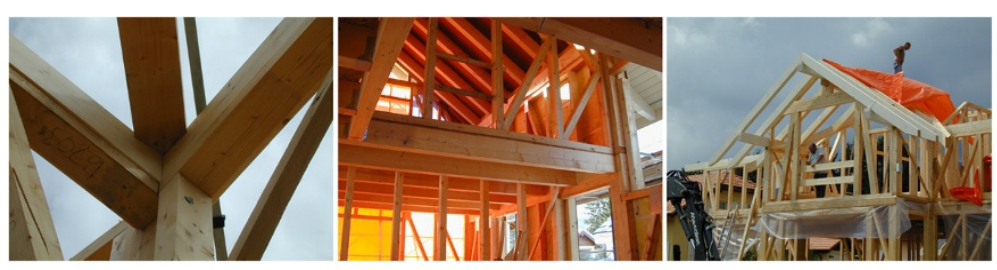

Figure 1 Structures built by carpenters. Examples of such structures. 
3. Determine how much wood will be needed, select and prepare it.

4. Cut the various pieces of wood as indicated on the plan.

5. Go to the construction site and assemble all the pieces together.

For all the steps but the third one, spatial skills play a key role. At the end of the apprenticeship, a carpenter must be able to perform all these steps correctly.

The carpenter apprenticeship currently lasts for three years (it will be extended by one year, starting in 2014). Following the general VET scheme, the training happens in 3 places: the professional school (1 day a week), the company (4 days a week), and the inter-company courses, a few weeks per year for a total of 32 days over the 3 years.

\section{Contextual inquiry in professional schools and companies}

In preparation to this study, visits to the schools and to the companies revealed the different perspective that stakeholders from professional schools and companies have on how to train professionals.

Overall, company directors and teachers from professional schools agreed on one point: being a carpenter requires excellent spatial skills. Indeed the information regarding the physical, 3D items that carpenters have to build is conveyed by means of 2D paper plans. Tasks such as transitioning from the paper plans to the final object and imagining how several beams are going to fit together are carpenters' bread-and-butter and require excellent spatial skills.

From the visits at the schools as well as the studies of the learning material provided to carpenter apprentices, we established that about $60 \%$ of the profession-specific teaching time is dedicated to drawing. This includes activities such as learning the basics of descriptive geometry and how to draw carpentry plans. The remaining $40 \%$ are split between learning the required mathematics subjects applied to carpentry as well as studying physics building, building materials, and structural mechanics.

However, in light of this learning curriculum, the bottom line from the company stakeholders' was that schools had not adapted to the changes that the profession had undergone With the recent advent of new technology such as computer-aided design (CAD) software and computerized numerical control (CNC), and with the new construction standards, the needs for training of new carpenters had drastically changed. According to them, the need to learn drawing for new generations of carpenters is much weaker than it was before.

When interviewed at work and at school, apprentices confirmed that, in the workplace, they almost never draw anything, since most of the plans are made by their supervisor, be it with a CAD software or by hand. While not all of them disliked drawing, most of them said they did not understand why they have to spend so much time learning how to draw when drawing will most likely never be part of their work tasks.

The teachers, on the other hand, had a different take on the subject: they insisted on the fact that drawing was the basis of the profession and that it should definitely not be abandoned. They acknowledged that drawing was not per se used in the professional environment anymore, but emphasized that it was key to learn the concepts of the profession, helped apprentices learn to read plans, and helped develop their spatial skills. 


\section{Overview of spatial skills \\ Definition of spatial skills}

Spatial cognition addresses how humans acquire and encode spatial information, and how it is represented in memory and manipulated internally (Quarles et al. 2008; Hegarty et al. 2006). It is a specific and important kind of cognition, to the point that Gardner (2006), in his original theory on multiple intelligences, identified spatial intelligence as one of the seven types of intelligence that humans possess.

Although various classifications of spatial skills have been proposed, a separation into two main dimensions is usually accepted: visualization (e.g. mental rotation, paper folding) and navigation (e.g. map orientation). These two dimensions have also been defined as "scales" of spatial ability (Hegarty et al. 2006), with visualization being considered small-scale and navigation large-scale. Capability in each of these two dimensions may be independent. Uttal et al. (2012) have defined four other classifications that are based on the type of information that a task requires (extrinsic versus intrinsic) and whether it is dynamic or static. For example, a mental rotation task would be classified as dynamic (one has to mentally turn the object) and intrinsic, since it requires a comparison of the parts of an object, as opposed to a comparison of the object with its environment.

For carpenters, while multiple types of spatial skills are certainly useful, the most needed one is visualization (or intrinsic, both static and dynamic). This is the skill that allows them to go back and forth between the 2D representation of an object, given by the plan, and the 3D object itself. With good spatial skills, they can imagine, based on a plan, how a building will look like, how beams will be assembled, or check on a plan whether what they built is correct.

In the rest of article, "spatial skills" refers to the spatial visualization skills that carpenters use to imagine a 3D object from a 2D paper representation, and the other way around. For carpenters, the 2D representation is given by orthographic projections, which are a kind of parallel projection where all projection lines are orthogonal to the projection plane. Figure 2 shows the orthographic projections and a perspective 3D representation of it. The 3D object can be mentally elaborated by cross-checking information on the 3 orthographic projections if there are no coinciding projections of vertices (Lafue 1976).

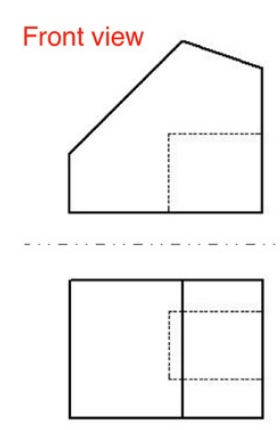

Top view

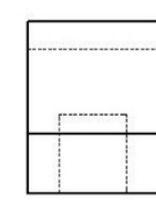

Side view

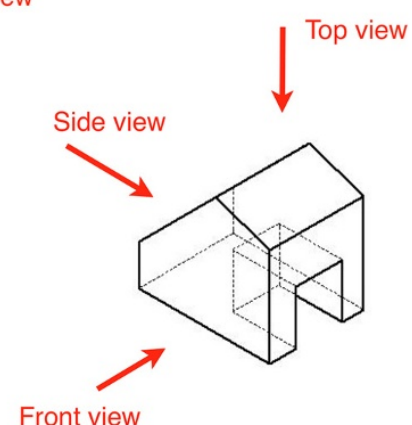

Front view

Figure 2 Orthographic projections. 


\section{Importance of spatial skills}

As pointed out by Sorby (2009), "spatial skills have been a significant area of research in educational psychology since the 1920s or 30s". Educational systems, though, have often neglected and looked down on visual thinking, favoring instead other cognitive skills (Sommer 1978, Arnheim 1980; Smith 1964; Gardner 2006). In the last decades, the interest for spatial skills has increased, leading to a growing body of research on understanding, assessing, and developing means of training spatial skills.

In a study involving 400,000 participants of grades 9 to 12 over 11 years, Wai et al. (2009) measured the link between spatial capability and STEM domains (science, technology, engineering, and mathematics). Their results showed that spatial capability has a strong influence on the development of expertise in STEM fields. For example, individuals holding at least a Bachelor's degree in engineering have spatial skills that are more than one-and-a-half standard deviation higher than the rest of the population. Other researchers also suggested that spatial capability assessment could be used to improve the detection of teenager talents for the STEM domains (Shea et al. 2001), or that improving mathematics and science skills could be achieved by enhancing spatial thinking (Newcombe 2010; Sorby et al. 2013). Another possibility might be that improving spatial skills could reduce the number of university dropouts in engineering studies (e.g. (Sorby 2009)).

Spatial skills are not only important for school subjects. In the professional world, spatial visualization skills and mental rotation capabilities are important for technical professions (Maier 1994). The professions that come first to mind are those that require a high level in STEM domains, such as mechanical engineer and architect. However, there are also some more unexpected professions for which spatial skills play an important role. For instance, Hegarty et al. (2009) showed that dentistry students develop mental models of teeth. Hambrick et al. (2011) found that novice geologists' spatial capability was correlated with their score at geology mapping tasks and concluded that specifically training spatial capability could benefit especially young professionals. Several studies showed the importance of spatial thinking for chemical sciences (e.g. Carter et al. (1987)). Hamlin et al. (2006) showed that a person's spatial capability influences his or her capability to learn and use 3D modeling software.

For a long time, there was a wide spread belief that one is born with a given potential for spatial thinking and that this potential is fixed. In fact, skepticism about the malleability of spatial skills was persistent for many years even among researchers, with many of them arguing that training spatial skills only leads to short improvements, and only in cases where the training and measurement tasks are very similar (e.g. (Sims and Mayer 2002)). However, in the most recent and comprehensive meta-analysis to date on spatial skills training, (Uttal et al. (2012), p. 27) found that spatial skills were "moderately malleable and that training, on average, improved performance by almost half a standard deviation".

\section{Goal of this study}

The importance of spatial skills reported by both the carpentry teachers and the directors of carpentry companies is coherent with the finding that technical professions require some well-developed spatial skills. The literature, however, provides mainly insights on spatial skills of high school and university students. We lack knowledge about spatial 
skills of apprentices in initial vocational training and even more so of specifically carpenter apprentices. This study pursues the goal of finding (1) whether carpenter apprentices indeed have well-developed spatial skills compared to other populations, and (2) whether their spatial skills improve throughout their initial vocational training. Formally, this means that we have two hypotheses:

$H_{A}$ The spatial skills of carpenter apprentices are higher than those of same age individuals that do not attend a carpentry training.

$H_{B}$ The spatial skills of carpenter apprentices improve over the course of their apprenticeship.

\section{Methods}

To verify these two hypotheses, the first step was to create testing material (see next paragraph). Answering $H_{A}$ required comparison populations. Two target populations, besides carpenters, were chosen so as to represent various samples of the population: apprentices of another profession (logistics apprentices with whom we had worked in a previous research project), and more academically oriented subjects (high school students). The results concerning $H_{A}$ are discussed in the first part of the results section.

As for $H_{B}$, there are two ways to test it: compare the performance of apprentices enrolled in different years of the apprenticeship, or compare the performance of the same apprentices several times over time. The results of both approaches are reported in the second part of the results section.

\section{Testing material}

There exist several tests to measure spatial skills. The one used in this study consists of three parts: mental rotation (MR), paper folding (PF), and orthographic projection (OP). The MR and PF parts are taken from two widely used tests to measure mental rotation and spatial visualization capabilities, respectively (Peters et al. 1995; Ekstrom et al. 1976), these being the main tests used in the literature. The mental rotation test comprises of two series of 12 questions, and the paper folding test is made of two series of 10 questions. The MR and PF tests were chosen for this study because they are the main tests used in the literature. The orthographic projection part was designed specifically for this test and is composed of 6 questions that require the participant to match a 3D perspective view of an object with a $2 \mathrm{D}$ one. These additional items were added so that the test be closer to the practice of carpenters.

Example questions of each of the three parts are shown in Figure 3. For the mental rotation test, two of the four figures on the right are a vertical rotation of the left image (Figure 3A). The participant must identify these two figures. For the paper folding test, a square piece of paper is folded and then punched as shown on the left (Figure 3B). The participant must find which one of the five figures on the right matches the piece of paper, once it is unfolded. For the orthographic projections, there are two types of questions. In the first type (Figure 3C), the participant must tell which one of the four $3 \mathrm{D}$ models matches the three orthographic projections. In the second type (Figure 3D), a perspective representation of the model is shown and the subjects must determine which one of the four $2 \mathrm{D}$ drawing matches the $3 \mathrm{D}$ model when seen as shown by the arrow. 


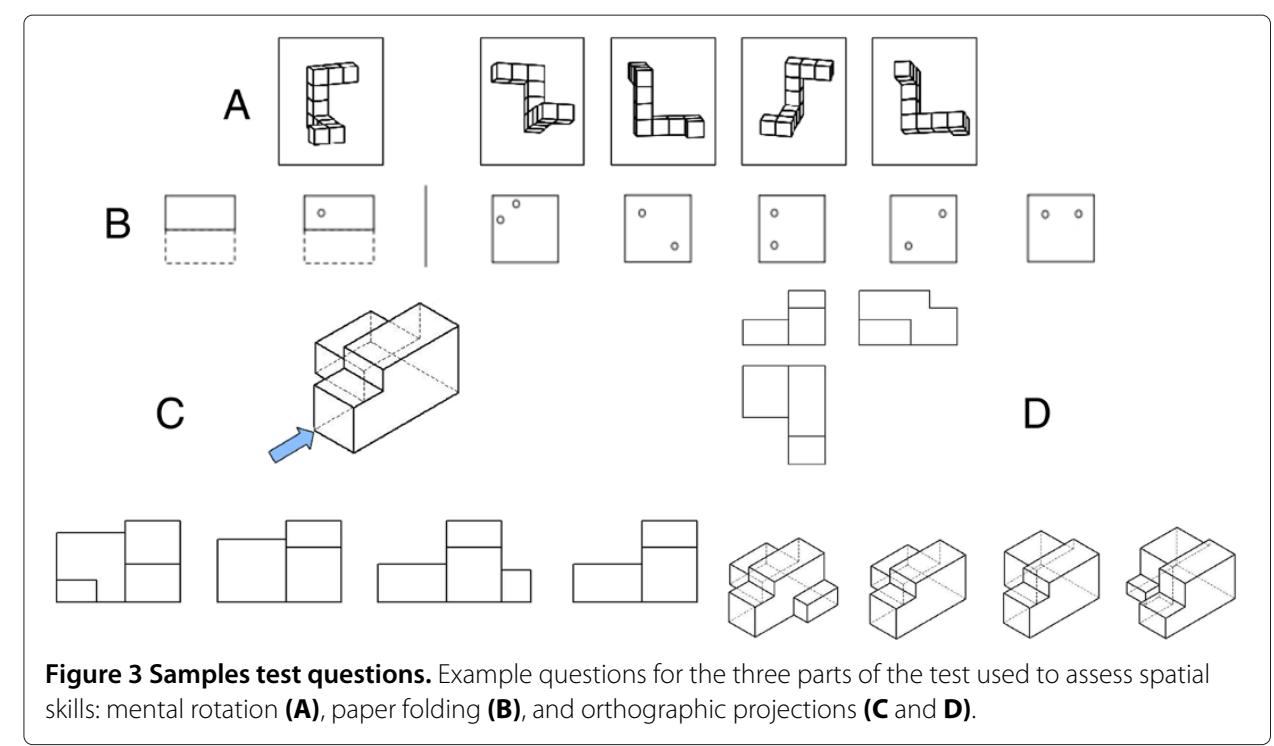

\section{Participants}

A total of 726 subjects (98 females) were tested. The subjects were either carpenter apprentices, logistics apprentices, or high school students. Their age ranged between 14 and 40 years, with an average age of 18 . Tables 1 and 2 summarize the data by year and by gender for the three separate types of curriculum. The duration of each curriculum is three years, but practical constraints allowed us to gather third year data for carpenters only. For the years 1,2 , and 3, the tests were taken at the very end of the academic year, meaning that year 1 students already had an entire year of training behind them. Subjects referred to as in year 0 were tested two weeks after the start of their first year of training. This was the most practical way to get a given population of subjects together while minimizing the effect of prior training.

\section{Testing procedure}

The test was done on paper, lasted for 35 minutes and was taken in the classroom by all students of the class at the same time. The teacher was present during the test. Participants were not allowed to communicate for the duration of the test. A timed PowerPoint presentation displayed the instructions and served as time keeper for the test to ensure equality of treatment among the subjects in the various classes. The instructions included sample questions with answers to ensure that participants understood the task. For the parts of the tests that had two series of questions (MR and PF), a 90 second break was given to the participants between the two series.

Table 1 Number of subjects by year and by curriculum

\begin{tabular}{lccccc}
\hline & \multicolumn{3}{c}{ Year } & $\mathbf{3}$ & All \\
\cline { 2 - 6 } Curriculum & $\mathbf{0}$ & $\mathbf{1}$ & 148 & 65 & 440 \\
\hline Carpenter & 77 & 38 & 48 & 0 & 153 \\
Highschool & 67 & 68 & 30 & 0 & 133 \\
Logistician & 35 & & $\mathbf{2}$ & \\
\hline
\end{tabular}


Table 2 Number of subjects by gender and by activity

\begin{tabular}{lcc}
\hline & \multicolumn{2}{c}{ Gender } \\
\cline { 2 - 3 } Curriculum & Female & Male \\
\hline Carpenter & 1 & 439 \\
Highschool & 79 & 74 \\
Logistician & 18 & 115 \\
All & 98 & 628 \\
\hline
\end{tabular}

\section{Scoring}

Each correct answer was rewarded with one point. Each question in the PF and OP parts of the test had one correct answer and therefore yielded 0 or 1 point, while the MR questions each had a maximum of two correct answers, and therefore yielded 0,1 , or 2 points. The final score of the test was computed as an average of the percentage score of each part of the test, with an equal weight of one third for each of them:

$$
\text { score }=\frac{1}{3} \cdot S_{M R}+\frac{1}{3} \cdot S_{P F}+\frac{1}{3} \cdot S_{O P}
$$

where $S$ denotes the percentage score of the given part of the test.

\section{Data pre-processing}

The data needed to be processed in two ways to allow comparison across the three populations. First, given the correlation between spatial skills and gender reported in the literature

girls were excluded from the data (in accordance with the literature, our results showed a significant gender difference in favor of males $(\mathrm{F}[1,724]=24.1, \mathrm{p}=.000))$.

Second, only carpenters had data for the third year. To avoid a potential year effect, the third year carpenters were removed from the data for the population comparison. They will be reintroduced when comparing the progression over time within the carpenter sample in the second part of the results section presented now.

\section{Results and discussion}

\section{Results on $H_{A}$ : Population differences}

Comparing populations on the overall score

A comparison of the overall score of the three populations with all males enrolled in year 0 to 2 showed no significant difference between the carpenters and the high school students, but revealed a significant difference between the logisticians and the rest of the subjects $(\mathrm{F}[2,560]=56.23, \mathrm{p}=.000)$, as shown in Figure 4 .

Spatial skills are often partially correlated with the general school level, and the general school level of carpenter apprentices is admittedly lower than that of high school students and comparable to that of logisticians (Stalder 2011). This means that carpenters' spatial skills should be close to those of logisticians, but lower than that of high school students.

However, as can be seen in Figure 4, the carpenter's performance is significantly higher than the logisticians' and identical to the high school students', suggesting that carpenters apprentices' spatial skills are higher than expected.

Noteworthy is the fact that the spatial skills of carpenters were already strong at the beginning of their training. In particular, as can be seen in Figure 4, their performance in year 0 was similar to that of high school students and significantly higher than that of 


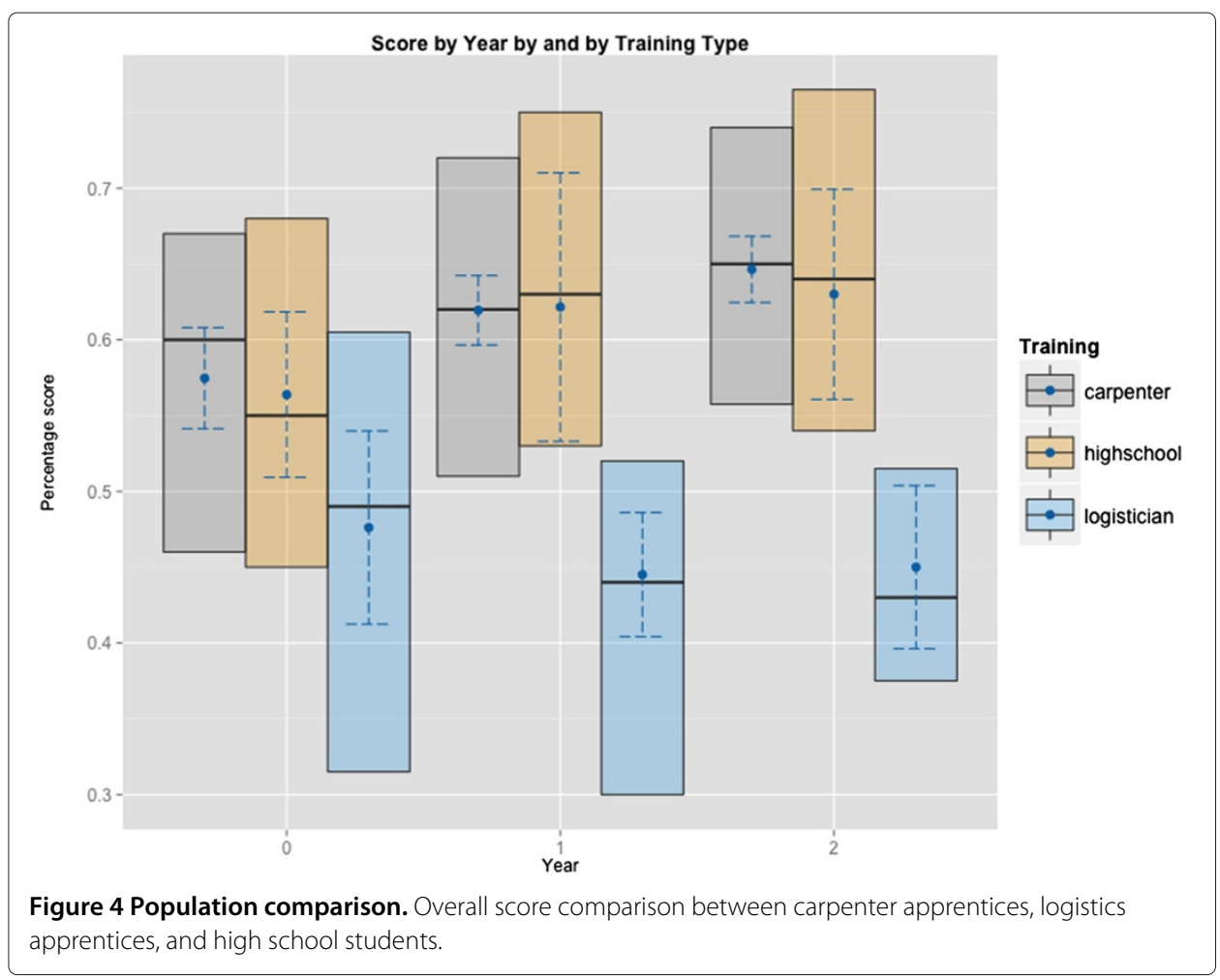

logisticians $(\mathrm{F}[1,110]=9.6, \mathrm{p}=.002)$. This indicates that there is a selection effect prior to the start of the apprenticeship, be it a self-selection or an employer-motivated selection effect.

\section{Comparing populations for each part of the test separately}

We now look at the results for each sub-part of the test (Figure 5), as it can indicate where the difference of performance between the populations came from. The carpenters significantly outperformed the logisticians in all parts of the test. The high school students' and the carpenters' scores are close for the paper folding and the orthographic projection parts, but the carpenters' score is significantly higher for the mental rotation part $(\mathrm{F}[1,446]=6.42, \mathrm{p}=.01)$.

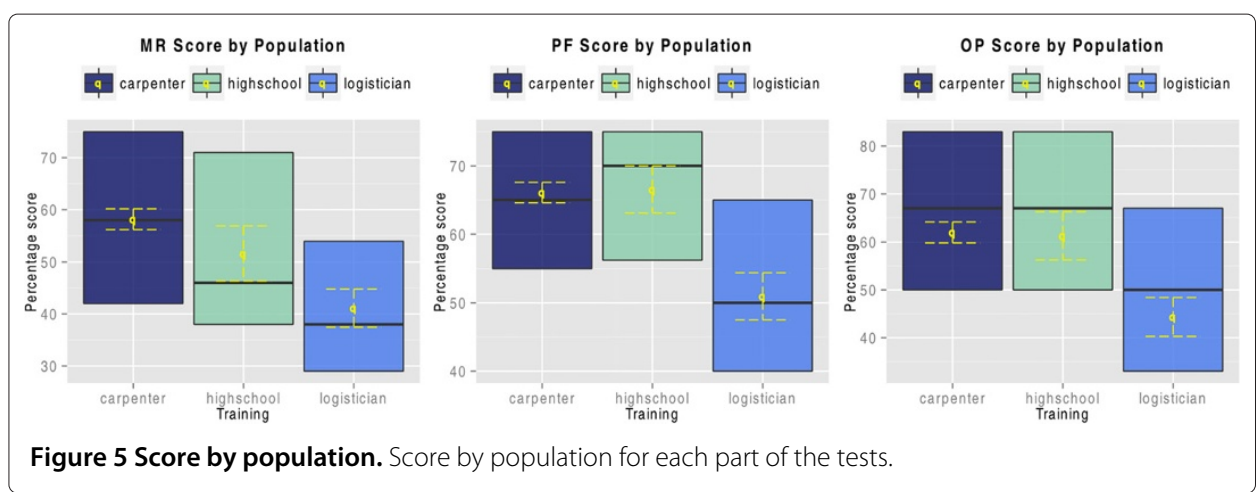




\section{Comparison with previous research}

Comparing the carpenters' scores with previous results reported in the literature can give an indication of the carpenters' performance. There are many studies in which scores on the mental rotation test have been reported, almost all of them with undergraduate students as participants. For paper folding, there is a greater variety of tests, and therefore fewer studies with which the results of the current study can be compared. Moreover, some studies do not report the raw results required for a statistical comparison (mean and standard deviation, separated by gender). In the end, we selected three studies for mental rotation and two for paper folding. The tests used in the selected studies were the same as those used in the current study.

For mental rotation, Peters et al. (1995) tested 237 male Bachelor students, 102 in Arts, and 135 in Science, with an average age of 21.3. Art students scored 50.4\% (standard deviation (SD): $20.0 \%$ ) on average, and science students got a mean score of 61.7\% (SD: 20.0\%). In comparison, the 439 male carpenter apprentices tested in the current study got a mean score of 58.1\% (SD: 19.8\%). According to a t-test, the carpenters' performance is significantly higher than the Arts students' $(\mathrm{t}[539]=-3.53, \mathrm{p}=.000)$, but not significantly different from the Science students' $(\mathrm{t}[572]=1.84, \mathrm{p}=.66)$. Another study involved 139 male introductory psychology students (Voyer and Saunders 2004). The mean age of the participants was 19.8, and their average score, $60.7 \%$ (SD: 18.9\%), which is not significantly different from the carpenters' performance $(\mathrm{t}[576]=1.36, \mathrm{p}=.17)$. A third study (Gouchie and Kimura 1991) tested 42 volunteer males (mean age 21.0), mostly undergraduate students. They scored $45.8 \%$ (SD: $39.0 \%$ ), which is significantly lower than the carpenters' score $(\mathrm{t}[479]=-3.44, \mathrm{p}=.001)$.

In the same study (Gouchie and Kimura 1991), the participants also took the paper folding test (although they used only one of the two parts of the test used in the current study, i.e. 10 questions instead of 20). Their performance (mean $=62.9 \%, \mathrm{SD}=20.8 \%$ ) was lower than the carpenters' (mean $=66.4 \%, \mathrm{SD}=14.6 \%$ ), although not significantly $(\mathrm{t}[479]=-1.42, \mathrm{p}=.16)$. Kimura (1994) measured the performance of 24 undergraduate male students (no mention of age) to 66\% (SD: 24.0\%), again using only 10 questions of the paper folding test. The performance was not significantly different from the carpenters' performance $(\mathrm{t}[545]=-.22, \mathrm{p}=.83)$.

These comparisons with previous research show that the carpenter apprentices' performance on either the mental rotation or the paper folding test was as high, and even higher in some cases, than first year university students' performance. This result goes along the same line the one above that showed that carpenter apprentices' performance was similar to that of high school students and significantly higher than that of logistics apprentices. Together, these two results confirm the first hypothesis $\left(H_{A}\right)$ : The spatial skills of carpenter apprentices are higher than those of same age individuals that do not attend a carpentry training.

We now turn to the second hypothesis $\left(H_{B}\right)$, which can be reformulated as a question: are these skills high by nature, or do they develop over the course of the apprenticeship?

\section{Results on $H_{B}$ : Improvement over time}

One way to look at the progression over time is to compare the performance of the apprentices in year 0 with the performance of the apprentices in year 3. However, this makes the assumption that, on average, each yearly batch of apprentices started their 
apprenticeship with the same spatial skills level. Another way to measure the progression over time that gets rid of this assumption is to measure the actual skill improvement over time by testing the same apprentices twice: once at the beginning of their apprenticeship, once towards the end of it. The results of both approaches are presented below.

\section{Different students on different years}

The 439 male carpenters were spread over the 4 years (see Table 1). Figure 6 shows that carpenters tend to improve slightly over the course of their apprenticeship. According to a linear model fitted by regression (shown in the Figure as a line), the average score improvement for each year of training was $2.2 \%$, which is a significant improvement $(\mathrm{F}[3,437]=4.65, \mathrm{p}=.003)$. Although the $2.2 \%$ average improvement per year is statistically significant, comparing the results of the years two by two with a pairwise $t$-test tells a slightly different story. Indeed, while the score for year 0 is significantly different from that of the three other years, the year-to-year comparison of the performance in year 1,2, and 3 shows no statistical differences.

This is a contrasted result: on the one hand there is a significant improvement over the four years tested, but on the other hand the improvement seems to come mostly from the lower result of participants tested in year 0 . This could indicate that spatial skills improve strongly during the first year of the apprenticeship, and then only marginally. It could also be due to the drastic selection that occurs in the first year of the carpenters' training, where about one third of the apprentices fail. The significant improvement over time found for carpenters does not appear for the two other populations $(F[1,72]=2.62, p=$ 0.11 for high school students, $F[1,113]=0.44, \mathrm{p}=0.50$ for logisticians), although the non significance of the statistical result might also be due to the smaller sample size of those two groups.

\section{Same students two years apart}

A second way to measure whether the spatial skills level of carpenter apprentices improves during their apprenticeship is to test them twice during their apprenticeship: once at the beginning, and once towards the end of it. In the spring of 2012, two years

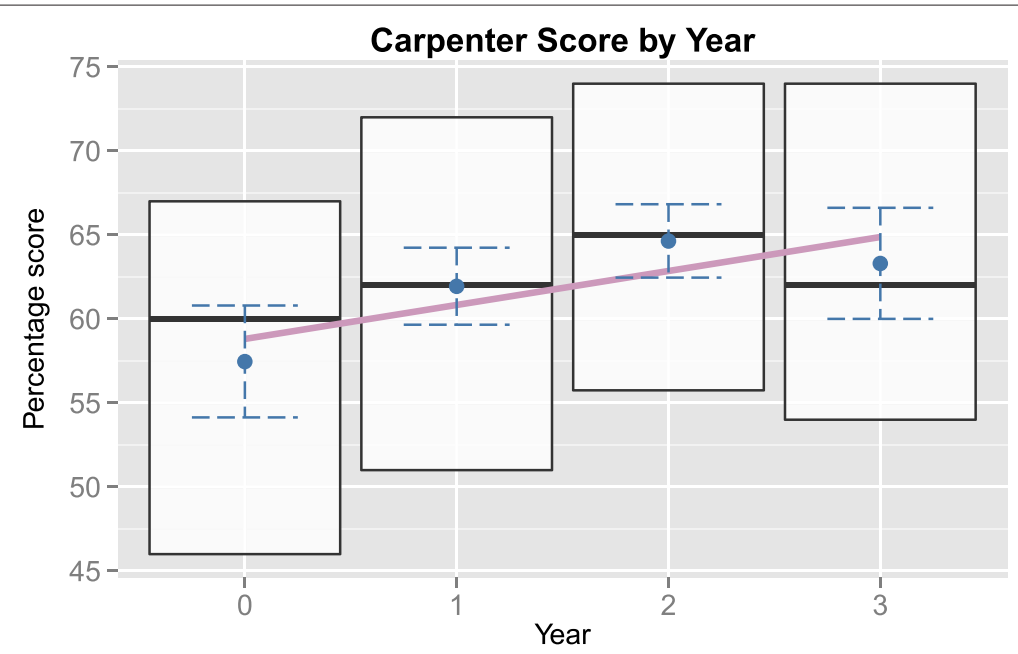

Figure 6 Score by year. The overall score for carpenter participants split by year. 
after the first round of tests, a subset of the same carpenter apprentices - those who were still doing their apprenticeship - were administered the same test a second time.

Data In total, 120 male apprentices took the test twice. In order to be able to make cleaner comparisons, 9 apprentices who had repeated a year were removed from the data set. The final sample size was 111, with 41 apprentices in year 0 in 2010 and in year 2 in 2012, and 70 apprentices in year 1 in 2010 and year 3 in the 2012. In the rest of this section, those two groups are refered to by the year in which they were enrolled in in 2010, i.e. year 0 and year 1 .

Results Table 3 shows the 2010 and 2012 performance for three different groups: all students together, only year 0 students, and only year 1 students. For each of these groups, the details for each part of the test are also shown. On top of the percentage scores of 2010 and 2012, the table shows the relative learning gain (RLG) between 2010 and 2012, and the statistical significance of the difference between the two scores, computed with a two-sample paired t-test. The RLG was computed as shown in Equation 1, where pre and post are the percentage scores for the test in 2010 and 2012, respectively.

$$
R L G=\left\{\begin{array}{l}
100 \times\left(\frac{\text { post-pre }}{100-\text { pre }}\right), \text { if }(\text { post }- \text { pre })>0 \\
100 \times\left(\frac{\text { post-pre }}{\text { pre }}\right), \text { if }(\text { post }- \text { pre }) \leq 0
\end{array}\right.
$$

There are other ways to report learning gain (score difference, percentage increase, etc.), but the RLG has the advantage of not penalizing students who scored well on the pretest, because it measures the improvement achieved on the possible improvement from the pre-test score.

Improvement over the two years There was a significant and positive global RLG between the 2010 and the 2012 scores (26.4\%). The mean percentage score went from $62.8 \%$ to $72.6 \%(\mathrm{~F}[1,110]=95.78, \mathrm{p}=.000)$. Even when looking at the parts of the test separately, each of them displays a strong and statistically significant improvement when measured on all students. The improvement was stronger than for the results reported

\begin{tabular}{|c|c|c|c|c|c|}
\hline Group & Part & 2010 & 2012 & RLG & Significance \\
\hline \multirow{4}{*}{ Year 0} & $\mathrm{MR}$ & 60.0 & 70.1 & $29.3 \%$ & $t[40]=-3.32, p=.002$ \\
\hline & PF & 61.3 & 73.9 & $30.7 \%$ & $t[40]=-3.26, p=.000$ \\
\hline & $\mathrm{OP}$ & 63.0 & 67.9 & $20.6 \%$ & $\mathrm{t}[40]=-1.27, \mathrm{p}=.21$ \\
\hline & all & 60.9 & 71.4 & $27.4 \%$ & $\mathrm{t}[40]=-6.11, p=.000$ \\
\hline \multirow{4}{*}{ Year 1} & $\mathrm{MR}$ & 60.6 & 71.8 & $27.5 \%$ & $\mathrm{t}[69]=-5.53, p=.000$ \\
\hline & PF & 68.8 & 76.4 & $27.4 \%$ & $\mathrm{t}[69]=-5.31, p=.000$ \\
\hline & $\mathrm{OP}$ & 61.0 & 69.8 & $25.6 \%$ & $\mathrm{t}[69]=-3.54, p=.001$ \\
\hline & all & 63.9 & 73.4 & $25.8 \%$ & $\mathrm{t}[69]=-7.60, p=.000$ \\
\hline \multirow{4}{*}{ Year 0 and 1} & $\mathrm{MR}$ & 60.4 & 71.2 & $28.2 \%$ & $\mathrm{t}[110]=-6.37, p=.000$ \\
\hline & $\mathrm{PF}$ & 66.0 & 75.5 & $28.7 \%$ & $t[110]=-8.19, p=.000$ \\
\hline & $\mathrm{OP}$ & 61.7 & 69.1 & $23.8 \%$ & $t[110]=-3.49, p=.001$ \\
\hline & all & 62.8 & 72.6 & $26.4 \%$ & $\mathrm{t}[110]=-9.79, p=.000$ \\
\hline
\end{tabular}


in Figure 6: it went from a $2.2 \%$ average yearly improvement to a $4.9 \%$ average yearly improvement. This could be the result of the selection effect incurred by the removal of students redoing a year from the second set of data. Indeed, when taking into account only the years 0,1 , and 2 from the results in Figure 6, the yearly improvement goes up from $2.2 \%$ to $3.6 \%$ (57.5\% in year 0 to $64.6 \%$ in year 2$)$.

Improvement for each part of the test When further splitting the students per year, the only non-significant result is the orthographic projection part for the year 0 group. In parallel, on the same part of the test, year 1 apprentices did improve significantly. This suggests that the improvement on the carpentry specific part is linked to the second and third year of the apprenticeship, rather than the first year of it. It is surprising, because what was tested in the carpentry part (orthographic projections) is already taught in the first year.

There are several explanations for this. One is that apprentices need some time to master orthographic projections, and longer exposure to them, both at work and at school, increases their performance. The fact that the performance on the other parts of the test improved could reflect the higher degree of specialized knowledge required for the orthographic projections. By comparison, the MR and PF tasks are purely spatial reasoning tasks and do not require extra knowledge. Another reason could be that the test did not capture improvement as well as the MR and PF parts, which had more questions and which benefited from more effort and meticulousness from psychologists in the design of the questions. Last but not least, the similarity between the OP part and the school exercises might have reduced the apprentices' motivation.

\section{Limitations of the current study}

As already mentioned, measuring the progression by comparing different students enrolled in different years of the apprenticeship makes the assumption that the four batches of students started their apprenticeship with similar spatial skills. This assumption, although reasonable, cannot be verified. When measuring the progression in terms of score improvements of the same students within two years, there is a non measurable retest effect. Arguably, the retest effect two years apart is weak, but ideally, there should have been a control group to measure this retest effect.

Everything was done to ensure that the test conditions were the same for all subjects, especially time-wise, but practical constraints made it impossible to have the exact same conditions for all subjects. Subjects were tested on different days of the week, at different times, and with different surrounding school environments.

In the design of the test, a set of questions specific to the carpenters' curriculum (OP) was added to two widely used tests (MR and PF). In order to keep the total duration of the test under the duration of a lesson, the number of questions in the OP part was limited to six. Ideally, to be able to pinpoint exactly what difficulties participants had with orthographic projections, the OP part should have comprised about 20 questions. However, this would have pushed the test over the duration of a lesson, which would in turn have made the administration of the test difficult. The information brought by the OP part is therefore limited.

Finally, the way in which the score was computed could be discussed. For instance, no difference was made between a wrong answer and a missing answer, as it is sometimes 
the case in the literature. Also, the final score was computed as a weighted average of each of the three parts, with each of the three weights being equal. Other ways to compute the final score would have been to use weights proportional to the number of questions or to the time allotted to complete a specific part of the test.

Despite its limitations, this study fulfilled its goals by providing useful information on carpenters' spatial skills. In particular, it makes it possible to answer the two questions that were raised at the beginning of this section: whether carpenters have better spatial skills than other similar populations, and whether their spatial skills improve over the course of their apprenticeship.

\section{Conclusions}

Carpenters' spatial skills are higher than would be expected...

The first hypothesis $\left(H_{A}\right)$ was that carpenters had higher spatial skills than similar populations. This hypothesis was verified in two ways: through a first-hand comparison with high school students and logistics apprentices, and through a comparison with previously reported results of university students from the literature. The difference was found for different types of spatial tasks, i.e. mental rotation, paper folding, and orthographic projections. The results further showed that carpenter apprentices' spatial skills were already high at the beginning of their apprenticeship, indicating that there is a selection bias in the way carpenters are chosen or choose themselves their profession.

... and they improve

The second hypothesis $\left(H_{B}\right)$ was that carpenters' spatial skills improved over the course of their apprenticeship. The measurements were done in two ways, but showed similar results: carpenter apprentices' spatial skills performance increases over the years of the apprenticeship, and especially during the first year of their apprenticeship. We can therefore accept $H_{B}$, with the reservation that part of this improvement may be due to a selection bias (weaker students leave). Interestingly, while the performance on orthographic projections globally improved, it did not improve during the first two years, although orthographic projections are mostly taught during the first year at school. This suggests that the way orthographic projections are taught to carpenter apprentices can be improved.

\section{Implications for future work}

The verification of the two hypotheses complements the results of the contextual inquiry, which established that spatial skills are key for carpenters. The importance of spatial skills is evident in the selection process - whether it is a self-selection or a company-based selection - as well as in the training received by the apprentices. As spatial skills are crucial in this profession, there is a need to develop further solutions that encourage further improvement of teaching and learning activities for spatial skills.

One of these solutions are TUIs, a special kind of computer interfaces that allow the user to control the computer through the manipulation of physical objects. TUIs allow apprentices to learn with concrete learning material and hands-on activities, in a similar way as they currently do, and our first results using such technology are promising (Cuendet et al. 2012a; Cuendet et al. 2012b; Cuendet and Dillenbourg 2013). 


\section{Competing interests}

The authors declare that they have no competing interests.

\section{Authors' contributions}

SC and PD designed the tests. SC, EB, and CA carried out the studies in the classrooms. SC and EB carried out the statistical analysis. SC wrote the article with the help of JD. All authors read and approved the final manuscript.

\section{Author details}

${ }^{1}$ CHILI Lab, EPFL, Lausanne, Swizterland. ${ }^{2}$ EHB, Zollikofen, Swizterland. ${ }^{3}$ Stanford University, Stanford, CA 94305, USA.

Received: 11 November 2013 Accepted: 13 February 2014

Published online: 15 May 2014

\section{References}

Arnheim R (1980) A plea for visual thinking. Crit Inq 6(3): 489-497

Carter C, Larussa M, Bodner G (1987) A study of two measures of spatial ability as predictors of success in different levels of general chemistry. J Res Sci Teach 24(7): 645-57

Cuendet S, Bumbacher EW, Dillenbourg P (2012a) Tangible vs. virtual representations: when tangibles benefit the training of spatial Skills. In: Proc. NordiCHI 2012. ACM, New York, NY, USA

Cuendet S, Jermann P, Dillenbourg P (2012b) Tangible interfaces: when physical-virtual coupling may be detrimental to learning. In: Proc. British HCI 2012. British Computer Society, Swinton, UK, UK

Cuendet S, Dillenbourg P (2013) The benefits and limitations of distributing a tangible interface in a classroom. In: Proc. CSCL 2013. International Society of the Learning Sciences. Best paper award

Do-Lenh S, Jermann P, Cuendet S, Zufferey G, Dillenbourg P (2010) Task performance vs. learning outcomes: a study of a tangible user interface in the classroom. In: Proc. EC-TEL 2010. Springer-Verlag, Berlin, Heidelberg, pp 78-92

Ekstrom RB, French JW, Harman HH, Dermen D (1976) Manual for kit of factor-referenced cognitive tests. Educational Testing Service, Princeton, New Jersey

Gaillard L (2012) Perspectives de la formation - scénarios 2011-2020 pour le degré secondaire ii. Technical report, Office fédéral de la formation professionnelle et de la technologie OFFT

Gardner H (2006) Multiple intelligences: new horizons. Basic Books, New York

Gouchie C, Kimura D (1991) The relationship between testosterone levels and cognitive ability patterns. Psychoneuroendocrinology 16(4): 323-334

Hambrick D, Libarkin J, Petcovic H, Baker K, Elkins J, Callahan C, Turner S, Rench T, Ladue N (2011) A test of the circumvention-of-limits hypothesis in scientific problem solving: The case of geological bedrock mapping. J Exp Psychol Gen Vol 141(3): 397-403

Hamlin AJ, Boermsa N, Sorby SA (2006) Do Spatial Abilities Impact the Learning of 3-D solid Modeling Software? Proceedings of the Annual Conference of ASEE, Chicago, IL, CD-ROM

Hegarty M, Keehner M, Khooshabeh P, Montello DR (2009) How spatial abilities enhance, and are enhanced by, dental education. Learn Individ Differences 19(1): 61-70

Hegarty M, Montello DR, Richardson AE, Ishikawa T, Lovelace K (2006) Spatial abilities at different scales: individual differences in aptitude-test performance and spatial-layout learning. Intelligence 34(2): 151-176

Ishii H, Ullmer B (1997) Tangible bits: Towards seamless interfaces between people, bits and atoms. In: CHI '97. ACM, New York, NY, USA, pp 234-241

Jurdak M, Shahin I (2001) Problem solving activity in the workplace and the school: the case of constructing solids. Educ Stud Math 47(3): 297-315

Kimura D (1994) Body asymmetry and intellectual pattern. Pers Individ Differences 17(1): 53-60

Lafue G (1976) Recognition of three-dimensional objects from orthographic views. In: Proc. SIGGRAPH 1976, vol 10. ACM, New York, NY, USA, pp 103-108

Maier PH (1994) Räumliches Vorstellungsvermögenn. Peter Lang Frankfurt, Frankfurt

Manches A, O'Malley C (2012) Tangibles for learning: a representational analysis of physical manipulation. Pers Ubiquitous Comput 16(4): 405-419

Newcombe N (2010) Picture this: increasing math and science learning by improving spatial thinking. Am Educ 43: 29-35

Peters M, Laeng B, Latham K, Jackson M, Zaiyouna R, Richardson C (1995) A redrawn vandenberg and kuse mental rotations test: different versions and factors that affect performance. Brain Cognition 28(1): 39-58

Quarles J, Lampotang S, Fischler I, Fishwick P, Lok B (2008) Tangible user interfaces compensate for low spatial cognition. In: IEEE Symposium on 3D User Interfaces. IEEE, Reno, Nevada, USA, pp 11-18

Shea DL, Lubinski D, Benbow CP (2001) Importance of assessing spatial ability in intellectually talented young adolescents: a 20-year longitudinal study, Vol. 93

Sims V, Mayer R (2002) Domain specificity of spatial expertise: the case of video game players. Appl Cognit Psychol 16(1): 97-115

Smith IM (1964) Spatial ability: its educational and social significance. University of London Press, London

Sommer R (1978) The mind's eye: imagery in everyday life. Delacorte Press, U.S.

Sorby S (2009) Educational research in developing 3-d spatial skills for engineering students. Int J Sci Educ 31(3): 459-480

Sorby S, Casey B, Veurink N, Dulaney A (2013) The role of spatial training in improving spatial and calculus performance in engineering students. Learn Individ Differences 26: 20-29 
Stalder B (2011) Le niveau d'exigences intellectuelles des formations professionnelles initiales en suisse. classement des années 1999 à 2005. Technical report, Université de Bâle / TREE

Uttal DH, Meadow NG, Tipton E, Hand LL, Alden AR, Warren C, Newcombe NS (2012) The malleability of spatial skills: a meta-analysis of training studies. Psychol Bull 139(2): 352-402

Voyer D, Saunders KA (2004) Gender differences on the mental rotations test: a factor analysis. Acta Psychol 117(1): 79-94

Wai J, Lubinski D, Benbow CP (2009) Spatial ability for STEM domains: aligning over 50 years of cumulative psychological knowledge solidifies its importance. J Educ Psychol 101(4): 817-835

doi:10.1186/s40461-014-0003-3

Cite this article as: Cuendet et al: A study of carpenter apprentices' spatial skills. Empirical Research in Vocational Education and Training 2014 6:3.

Submit your manuscript to a SpringerOpen ${ }^{\circ}$ journal and benefit from:

- Convenient online submission

- Rigorous peer review

- Immediate publication on acceptance

$\checkmark$ Open access: articles freely available online

- High visibility within the field

- Retaining the copyright to your article

Submit your next manuscript at $\boldsymbol{\triangleright}$ springeropen.com 